\title{
Plasma total cysteine is a determinant of adiposity in healthy adolescents living in the Republic of Seychelles
}

\author{
A. J. McAfee ${ }^{1}$, M. S. Mulhern ${ }^{1}$, P. M. Ueland ${ }^{2}$, E. M. McSorley ${ }^{1}$, J. M. W. Wallace ${ }^{1}$, G. E. Watson ${ }^{3}$, \\ G. E. Myers ${ }^{3}$, E. van Wijngaarden ${ }^{3}$, C. Shamlaye ${ }^{4}$, P. W. Davidson ${ }^{3}$ and J. J. Strain ${ }^{1}$ \\ ${ }^{1}$ Northern Ireland Centre for Food and Health, University of Ulster, Coleraine, BT52 1SA, UK, ${ }^{2}$ Section for Pharmacology, \\ Institute of Medicine, University of Bergen, Bergen, Norway, ${ }^{3}$ University of Rochester, School of Medicine and Dentistry, \\ NY, USA and ${ }^{4}$ Ministry of Health, Victoria, Mahé, Republic of Seychelles
}

Plasma total cysteine (tCys) has recently been found to be positively associated with BMI and fat mass in large longitudinal studies ${ }^{(1,2)}$. Unlike other plasma amino acids, which are elevated in obesity, plasma tCys is suggested to be a determinant rather than a symptom of obesity, albeit through unconfirmed mechanisms ${ }^{(3)}$. The aim of the current study was to investigate associations between plasma tCys, along with other sulphur amino acids (SAA), and measures of adiposity in healthy adolescents aged 19-20 years and currently enrolled in the Seychelles Child Development Study.

Data previously collected from this cohort $(n=549 ; m=252, f=297)$ include BMI, waist circumference (WC) and \% body fat. Fasting blood samples were previously collected from which plasma concentrations of SAA (homocysteine (tHcy), methionine, tCys and cystathionine) and plasma lipids were analysed. In this cohort 18\%, 61\%, 12\% and 9\% subjects were classified according to their BMI $\left(\mathrm{kg} / \mathrm{m}^{2}\right)$ as being underweight, normal weight, overweight and obese respectively. Multiple linear regression analyses were carried out using adiposity measures as the dependent variable and SAA as the independent variable. Adjustments were also made for sex, participant education and plasma total cholesterol.

\begin{tabular}{|c|c|c|c|c|c|c|}
\hline \multirow[b]{2}{*}{ SAA $(\mu \mathrm{mol} / \mathrm{I})$} & \multicolumn{2}{|c|}{ BMI } & \multicolumn{2}{|c|}{ WC } & \multicolumn{2}{|c|}{$\%$ body fat } \\
\hline & $\beta$ & $\overline{P \text {-value }}$ & $\beta$ & $P$-value & $\beta$ & $P$-value \\
\hline \multicolumn{7}{|l|}{ Model 1} \\
\hline Methionine & -0.126 & 0.008 & -0.055 & 0.254 & -0.365 & $<0.001$ \\
\hline tCys & 0.167 & $<0.001$ & 0.187 & $<0.001$ & 0.153 & $<0.001$ \\
\hline Cystathionine & 0.099 & 0.044 & 0.04 & 0.418 & 0.120 & 0.011 \\
\hline \multicolumn{7}{|l|}{ Model 2} \\
\hline tHcy & -0.128 & 0.013 & -0.101 & 0.054 & -0.071 & 0.107 \\
\hline Methionine & -0.065 & 0.278 & -0.052 & 0.395 & -0.06 & 0.240 \\
\hline tCys & 0.134 & 0.004 & 0.165 & $<0.001$ & 0.092 & 0.022 \\
\hline Cystathionine & 0.096 & 0.063 & 0.048 & 0.366 & 0.054 & 0.222 \\
\hline
\end{tabular}

Model 1 was an unadjusted regression; Model 2 adjusted for sex, participant education and plasma total cholesterol. Significant results $(p<0.05)$ are bolded.

After adjusting for covariates, plasma tCys remained a significant positive predictor of BMI, WC and \% body fat and plasma tHcy remained a significant negative predictor of BMI. These results indicate that plasma tCys is associated with adiposity while plasma tHcy is associated with lower BMI in healthy young adults living in the Republic of Seychelles. In agreement with other studies, these effects were independent of plasma cholesterol and other plasma SAA ${ }^{(1,2)}$. Further research is needed to clarify the possible mechanisms involved in explaining a relationship between plasma tCys and adiposity.

This work was supported by grants from the US National Institute of Environmental Health Sciences, the National Institutes of Health and the Government of Seychelles.

1. Elshorbagy AK, Nurk E, Gram Gjesdal C et al. (2008) Am J Clin Nutr 88, 738-46.

2. Elshorbagy AK, Valdivia-Garcia M, Graham IM et al. (2011) Nutr Metab Cardiovasc Dis, ahead of print, dx.doi.org/10.1016/j.numecd.2011.01.008

3. Aasheim ET, Elshorbagy AK, My Diep T et al. (2011) Br J Nutr 106, 432-440. 